Artículo

\title{
Producción y evaluación de inóculos lácteos probióticos obtenidos del tracto digestivo de lechón (Sus scrofa domesticus) propuestos para alimentación porcina
}

Carmen Rojas Mogollón ${ }^{\text {a }}$

Gloria Ochoa Mogollón ${ }^{b}$

Rubén Alfaro Aguilera ${ }^{c}$

Javier Querevalú Ortiz ${ }^{\mathrm{d}}$

Héctor Sánchez Suárez ${ }^{\text {e* }}$

${ }^{a}$ Universidad Nacional de Tumbes. Facultad de Agronomía, Escuela de Agroindustria. Perú.

${ }^{\mathrm{b}}$ Universidad Nacional de Tumbes. Facultad de Ciencias de la Salud. Laboratorio de Biología Molecular. Perú.

${ }^{c}$ Facultad de Ciencias de la Salud. Laboratorio de Biotecnología. Biodes- Jefatura de práctica. Perú.

${ }^{d}$ Universidad Nacional de Tumbes. Facultad de Agronomía. Escuela de Agroindustria. Laboratorio de procesamiento de alimentos. Perú.

${ }^{\text {e }}$ Universidad Nacional de Tumbes. Facultad Ciencias Agrarias. Escuela de Medicina Veterinaria y Zootecnia. Perú.

*Autor de correspondencia: hsanchezs@untumbes.edu.pe

\section{Resumen:}

Con la finalidad de evaluar un inóculo lácteo (IL) probiótico, de bacterias ácido lácticas (BAL) nativas del lechón para ser usado como alimento (yogurt) en lechones, se tomaron muestras de la parte final del tracto digestivo (excretas) de diez lechones, criados en traspatio, sembradas en medio selectivo (agar MRS con azul de anilina). Para verificar su pureza, caracterizadas bioquímicamente y capacidad probiótica, se realizaron pruebas 
(tolerancia $\mathrm{pH}$ bajos, sales biliares y $\mathrm{NaCl}$ altos, pruebas oxidasa, catalasa, producción de gas y pruebas de antagonismo), identificación molecular por método estándar CTABDTAB. Para la elaboración del IL (yogurt), con cepas probióticas seleccionadas, reactivadas y homogenizadas (DO de 1 a $600 \mathrm{~nm}$ ), cada BAL fue activada en leche pasteurizada $(1 \mathrm{ml} / 100 \mathrm{ml})$ obteniendo mezcla uno y dos con las cepas 1, 5, 2 y 1, 5, 6 respectivamente. Evaluadas cada 5 días por 15 días en refrigeración. Molecularmente se identificó: 01 Lactobacillus reuteri, 04 Enterococcus faecium (BAL) y Escherichia fergusonii, Shigella flexneri (patógena). La selección de la BAL como probiótico fue por tolerancia $2.3 \times 10^{4} \mathrm{UFC} / \mathrm{ml}$ en $\mathrm{pH} 3.5 ; 7.00 \times 10^{3} \mathrm{CFU} / \mathrm{ml}$ en sal biliar al $5 \% ; 2.80 \times 10^{4}$ $\mathrm{CFU} / \mathrm{ml}$ en $\mathrm{NaCl}$ al 13\%. En viabilidad del inóculo lácteo (yogurt) fue obtenida siguiendo norma NTP 202.092:2014 e INEN 710 de 1996, en 15 días de almacenamiento refrigerado, siendo mejor la mezcla uno y la mezcla dos aceptable, con recuento de $10^{6}$ $\mathrm{UFC} / \mathrm{ml}$ y $10^{7} \mathrm{UFC} / \mathrm{ml}$ de células probióticas. Por lo tanto, son adecuados como inóculos lácteos probióticos para ser proporcionado vía oral a lechones.

Palabras clave: Lechones, BAL, Probióticas, Inóculo lácteo, Alimento inocuo, Antagonismo.

Recibido: 11/07/2019

Aceptado: 21/11//2019

\section{Introducción}

Los cerdos nacen sin flora bacteriana en su tracto digestivo, estos se infectan a medida que los anticuerpos maternos van desapareciendo, instalándose un patrón de microorganismos y producción de enzimas digestivas que se adaptan a cada etapa de digestión, evitando así el desequilibrio microbiológico. La flora bacteriana intestinal nativa del lechón, es cambiante ${ }^{(1,2)}$, coloniza, se reemplaza o pierde según la edad, tipo de alimento y cambios en el ambiente. Cuando se rompe el equilibrio microbiológico se genera el síndrome diarreico relacionado con el destete ${ }^{(3-6)}$.

Las bacterias ácido lácticas (BAL), forman parte de la microbiota intestinal normal de muchos animales y actúan como probióticos. Comparten características morfológicas, fisiológicas y metabólicas en común; son cocos o bacilos Gram positivos, no esporulados, inmóviles, anaeróbicos, microaerofílicos o aerotolerantes, son negativos a la oxidasa y catalasa. Asimismo, como principal producto de la fermentación de carbohidratos generan ácido láctico ${ }^{(2,7)}$, crecen a diferentes temperaturas y alta concentración de sal, toleran $\mathrm{pH}$ ácido o alcalino y son principales microorganismos utilizados como $\operatorname{probióticos}^{(3,8,9)}$. 
Los probióticos son microorganismos vivos que aportados en la dieta, beneficia el desarrollo de la flora microbiana en el intestino, estimulan las funciones protectoras del sistema digestivo, son bioterapéuticos, bioprotectores o bioprofilácticos ${ }^{(7,8,10)}$, capaces de producir compuestos antimicrobianos. El tiempo de reproducción es corto, tienen la capacidad de atravesar la barrera gástrica (secreciones del estómago y duodeno), debe ser estable durante el proceso de fabricación y comercialización, para que puedan llegar vivos al intestino. También actúan evitando la adhesión de bacterias patógenas en los receptores del epitelio intestinal ${ }^{(10)}$, neutralizando metabolitos tóxicos ${ }^{(7,9,11)}$ y se adaptan a una región determinada del intestino según la edad del lechón ${ }^{(3,12,13)}$.

En la nutrición del cerdo, los probióticos ayudan al establecimiento de la microbiota benéfica e inhiben a los enteropatógenos Escherichia coli y Salmonella typhimurium ${ }^{(3)}$. Asimismo, Lactobacillum plantarum, tiene potencial probiótico en lechones ${ }^{(14)}$, al igual que Rhodopseudomonas spp, Lactobacillus spp y Saccharomyces spp inhiben el crecimiento de Salmonella tiphymurium, L. acidophilus SS80 y Streptococcus thermophilus ${ }^{(15,16,17)}$. Además, los probióticos también están presentes en saliva y se recomienda que su utilización sea en la misma especie hospedera de la que fue aislada ${ }^{(9}$, 10).

Estos probióticos pueden ser suministrados como IL (yogurt), que es un producto sin acidificación excesiva, donde las BAL son viables a la incubación y almacenamiento; existiendo cepas tolerantes al tiempo como L. acidophilus y otros que se deterioran rápidamente en refrigeración cuando se utiliza Lactobacillus bulgaricus ${ }^{(18,19,20)}$. La mayoría de microorganismos utilizados para fabricar yogurt son comerciales. La leche de vaca y cabra son utilizadas para preparar yogurt, el cual tiene buena sinéresis, viabilidad de las BAL y características probióticas ${ }^{(17,18,20)}$; su consumo mejora la eficiencia alimenticia y evita contraer enfermedades gastrointestinales ${ }^{(5,19,20)}$ siendo de poco uso para la alimentación animal.

Bajo este contexto, se planteó producir un inóculo lácteo con BAL nativas aislados del tracto digestivo del cerdo, caracterizados fenotípicamente y genotípicamente y con propiedades probióticas e inocuo para la alimentación de lechones.

\section{Material y métodos}

\section{Población y muestra}

Se utilizaron 10 lechones de traspatio, de 35 días de edad, en lactación, alimentados con dietas sin antibióticos, provenientes del caserío El Limón, ubicado en el distrito Pampas

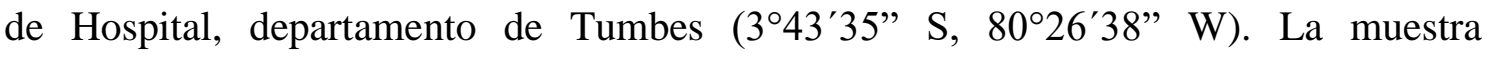
comprende bacterias ácido lácticas aisladas de la parte final del tracto digestivo (excretas). 


\section{Obtención de las muestras}

De cada lechón, se colectó excretas con hisopos estériles (raspado) y fue colocado individualmente en tubos plásticos estériles y herméticos, para ser transportados en cadena de frío ${ }^{(19)}$ hasta el Laboratorio de Biología Molecular ubicado en la Facultad de Ciencias de la Salud de la Universidad Nacional de Tumbes.

\section{Análisis microbiológico}

Se sumergió cada muestra en solución salina fisiológica estéril al $0.85 \%$ (diluyente), las diluciones se homogeneizaron por 5 a $10 \mathrm{seg}$ y se transfirió $1 \mathrm{ml}$ para los siguientes tubos con $9 \mathrm{ml}$ de caldo MRS, diluciones de $10^{-1}$ hasta $10^{-5}$ para recuento de colonias bacterianas. La siembra se realizó por el método de superficie, tomando $25 \mu \mathrm{l}$ de las diluciones decimales en placas con agar selectivo para BAL (agar MRS + Azul de anilina $0.13 \%$ ), seleccionando las colonias teñidas de azul (de la superficie del agar), las que se purificaron en agar MRS realizándose por el método de estría, verificando así la población de BAL, y se realizó la caracterización macroscópica por tamaño, forma, color, densidad, consistencia y tinción Gram para identificación ${ }^{(21,22)}$. Para la conservación se realizó en tubos con agar MRS inclinado con ángulo de $20^{\circ}$, sembrado por el método de estría, conservando a $4{ }^{\circ} \mathrm{C}$, crio preservados en medio TSB con glicerol al $30 \%$ a $-20{ }^{\circ} \mathrm{C}$, previa refrigeración ${ }^{(21,22)}$.

Para las muestras patógenas se procedió a la siembra por el método de agotamiento, en medios específico como: agar SS (salmonella, shiguella) y agar EMB (eosina azul de metileno $)^{(22)}$. Se aislaron, purificaron, identificaron y conservaron las cepas de las muestras, obtenidas de las excretas fluidas de lechones.

\section{Análisis bioquímico y pruebas de tolerancia}

A las cepas BAL aisladas y purificadas, se les realizaron pruebas para ser seleccionadas como probiótico: prueba de oxidasa, utilizando tiras de papel impregnadas con el reactivo para-amino-N-dimetil-anilina, que por la presencia de la enzima citocromo C-oxidasa, cambia el color, considerado positivo o negativo. Prueba de la catalasa, se observó la capacidad para desdoblar el $\mathrm{H}_{2} \mathrm{O}_{2}$ al $30 \%$, en agua y oxígeno, se verificó con el burbujeo intenso que puede determinarse como positivo o negativo (atribuida a la enzima catalasa) ${ }^{(16,23)}$. La generación de gas $\left(\mathrm{CO}_{2}\right)$, se verificó por el proceso fermentativo metabólico. Para las pruebas de tolerancia, se utilizó las cepas BAL seleccionadas, y cultivadas en caldo MRS a $37^{\circ} \mathrm{C}$ por $24 \mathrm{~h}$, se midió su crecimiento por densidad óptica $(\mathrm{DO}=1)$ a 600 nm en un espectrofotómetro UV y se utilizó un ml de BAL para cada prueba. Se evaluó la viabilidad mediante el recuento de bacterias en el agar MRS antes y después de incubación ${ }^{(15,16,23)}$. Tolerancia a pH bajos, en tubos falcón de $15 \mathrm{ml}$ de capacidad se añadió $10 \mathrm{ml}$ de caldo MRS ajustados a los $\mathrm{pH}$ 2.5, 3.5, 4.5 con $\mathrm{HCl}$. Tolerancia a sales biliares, en tubos falcón de $15 \mathrm{ml}$ de capacidad se añadió $10 \mathrm{ml}$ de caldo MRS enriquecidos con 1 
$\mathrm{g}(1 \% \mathrm{p} / \mathrm{v}), 5 \mathrm{~g}(5 \% \mathrm{p} / \mathrm{v})$ y $10 \mathrm{~g}(10 \% \mathrm{p} / \mathrm{v})$ de Ox-Bilis ${ }^{(15,16,23)}$. Tolerancia a concentraciones de $\mathrm{NaCl}$, en tubos falcón de $15 \mathrm{ml}$ de capacidad se añadió $10 \mathrm{ml}$ de caldo MRS enriquecidos con $5 \mathrm{~g}(5 \% \mathrm{p} / \mathrm{v}), 9 \mathrm{~g}(9 \% \mathrm{p} / \mathrm{v})$ y $13 \mathrm{~g}(13 \% \mathrm{p} / \mathrm{v}) \mathrm{de} \mathrm{NaCl}^{(15,16,23)}$.

\section{Actividad inhibitoria frente a microorganismos patógenos del lechón}

Consiste en el enfrentamiento de cada una de las cepas BAL seleccionada contra cada cepa patógena del lechón (E. fergusonii y S. flexneri). Se utilizaron las células y sobrenadantes según el método propuesto; se consideró como actividad inhibitoria positiva la observación del halo ${ }^{(2,15,16)}$. Las BAL y bacterias patógenas (homogeneizadas $\mathrm{DO}=1$; a $600 \mathrm{~nm}$ ), fueron conservadas en tubos con agar PCA inclinado y se activaron a $37^{\circ} \mathrm{C}$ por $24 \mathrm{~h}$ para su uso.

Método directo o por contacto. En placas de Petri se sembró la cepa BAL en agar MRS por técnica de hisopado, paralelamente en agar Mueller Hinton se sembró $25 \mu 1$ de la cepa patógena por técnica de superficie. De la placa con BAL se extrajo bocados circulares de $6 \mathrm{~mm}$ de diámetro y se colocaron sobre la placa con el patógeno ${ }^{(15,16)}$.

Método de pocillo sin neutralizar. Se sembró la cepa BAL en caldo MRS a $37^{\circ} \mathrm{C}$ por 24 h, se determinó el pH y se agregó $1 \mathrm{ml}$ del caldo en microtubos de 1.5 para centrifugar a $16,800 \mathrm{xg}$ durante $10 \mathrm{~min}$, obteniendo el sobrenadante para realizar las pruebas de antagonismo. Sembrando paralelamente en agar Mueller Hinton $25 \mu 1$ de la cepa patógena por el método de superficie, aquí se realizó perforaciones cilíndricas de $6 \mathrm{~mm}$ diámetro donde se agregó 35 a $40 \mu 1$ del sobrenadante de la BAL ${ }^{(15,16)}$.

Método de pocillo neutralizado. El procedimiento fue igual al método del pocillo sin neutralizar, cambia el sobrenadante, ya que este se neutralizó, ajustándolo a pH 7 con una solución de $\mathrm{NaOH} 1 \mathrm{~N}^{(15,16)}$.

\section{Análisis molecular}

Se realizó la identificación molecular de las bacterias BAL de lechones sanos y bacterias patógenas de lechón con diarrea, siendo la extracción de ADN, por el método estándar CTAB-DTAB de Gustincich, adaptado para células bacterianas ${ }^{(15,24)}$, para la PCR (Reacción en cadena polimerasa) se utilizó la amplificación del gen 16S ARNr, los cebadores universales 8F (5’ AGA GTT TGA TCC TGG CTC AG 3’) y 1510R (5’ GGT TAC CTT GTT ACG ACT T 3') descritos por Weisburg para estudios filogenéticos bacterianos, la electroforesis se realizó en gel agarosa al 1\%. Para la secuenciación de los productos de la PCR, se empleó $10 \mu \mathrm{l}$, se depositó en microtubos de $0.2 \mathrm{ml}$ porciones de $5 \mu \mathrm{l}$ de cada cebador universal para el gen 16S ARNr, los cuales fueron empacados y enviados para su secuenciación a la empresa Macrogen de Korea ${ }^{(15)}$. Las secuencias de ADN se alinearon con el software libre MEGA 7 y comparadas con las secuencias de $16 \mathrm{~S}$ 
ARNr, que se encuentra en la base de datos de acceso público del GenBank mediante el software libre BLAST (Basic Local Alignment Search Tool) ${ }^{(15,24)}$.

\section{Elaboración del inóculo lácteo (IL)}

La elaboración y evaluación del IL, se realizó según las normas del $\mathrm{INEN}^{(25)}$. Las etapas fueron, recepción de leche fresca, inspección organoléptica, tamizado, homogeneización mecánica $^{(21,26,27)}$, pasteurización, que se realizó a $75{ }^{\circ} \mathrm{C}$ por $10 \mathrm{~min}$, enfriamiento e incubación, que oscila entre los 40 y $45^{\circ} \mathrm{C}^{(26,27)}$.

Mezcla del inóculo lácteo. Se activaron las BAL seleccionadas con capacidad probiótica ${ }^{(28-29)}$, en agar MRS y se incubó a $37^{\circ} \mathrm{C}$ por 48 a 72 h según la cepa, una alícuota se sembró en $10 \mathrm{ml}$ caldo MRS y se incubó a $37{ }^{\circ} \mathrm{C}$ por $48 \mathrm{~h}$, para ser utilizada se homogeneizó a $\mathrm{DO}=1$; a $600 \mathrm{~nm}^{(26,27,28)}$. En frascos estériles de $250 \mathrm{ml}$, se agregaron 100 $\mathrm{ml}$ de leche pasteurizada y $1 \mathrm{ml}$ del caldo MRS con cepa BAL seleccionada y se incubó a $32{ }^{\circ} \mathrm{C}$ por $12 \mathrm{~h}$. Para la preparación de la mezcla final de IL (yogurt) se retiraron $50 \mathrm{ml}$ de cada inóculo anterior (por cepa) y se mezcló (cepas 1,2 y 5 y cepas 1,5 y 6) en medio litro de leche pasteurizada, se incubó a $32^{\circ} \mathrm{C}$ por $12 \mathrm{~h}$ y se conservó a $4{ }^{\circ} \mathrm{C}^{(27,28,)}$.

Análisis químico del inóculo lácteo. Se evaluó el $\mathrm{pH}$, acidez titulable, sinéresis y recuento de colonias a los $0,5,10$ y 15 días en refrigeración a $4{ }^{\circ} \mathrm{C}$. El valor de $\mathrm{pH}$ del $\mathrm{IL}$ se midió por el método 981.12 (AOAC, 1990) con el potenciómetro digital, calibrado, se tomó entre 40 a $45 \mathrm{ml}$ del IL en un recipiente, se introdujo el electrodo del pH y registró la lectura. Para la determinación de la acidez titulable, se tomaron $5 \mathrm{~g}$ de muestra, tres gotas de fenolftaleína, se homogeneizó y tituló con $\mathrm{NaOH} 0.1 \mathrm{~N}$, hasta obtener un color rosa pálido persistente (factor de fórmula 0.09 de ácido láctico) ${ }^{(29,30,31)}$. Para la evaluación de sinéresis, se utilizaron $10 \mathrm{~g}$ de muestra, se colocaron en tubos falcon, se centrifugó por 20 min a 4,200 xg; después de la centrifugación se obtuvo el peso del sobrenadante y se calculó el porcentaje de sinéresis (p/p) mediante la relación entre peso del sobrenadante y el peso de la muestra multiplicado por $100^{(31,32,33)}$.

Análisis microbiológico del inóculo lácteo. Se realizó teniendo en cuenta la identidad bacteriana para yogurt, empleado por NTP 202.092:2014, se utilizó el método ISO 7889:2003 (IDF 117:2003) según la enumeración de microorganismo característicos por la técnica de recuento de colonias a $37{ }^{\circ} \mathrm{C}^{(27,28,30,34)}$.

\section{Resultados y discusión}

\section{Evaluación del análisis microbiológico}

Se encontraron 10 cepas con características BAL después del descarte en agar MRS + azul de anilina y purificación en agar MRS, confirmados por método ${ }^{(16,23,29)}$, las BAL se tiñen de color azul intenso en el medio selectivo por la presencia de metabolitos de las 
colonias al reaccionar con el azul de anilina ${ }^{(23,24,29)}$; la literatura también confirma que las BAL son Gram positivas y pueden tener diferentes formas bacilos, coco y cocobacilos $^{(16,19,29)}$, así como observa en el Cuadro 1, donde también se presenta el crecimiento de las BAL siendo mayor la cepa $05\left(2.80 \times 10^{4} \mathrm{UFC} / \mathrm{ml}\right)$, seguido por la cepa $01\left(2.60 \times 10^{4} \mathrm{UFC} / \mathrm{ml}\right)$. Las cepas $04,09,07$ y 02 tuvieron valores similares; sin embargo, las cepas $03,06,08$ y 10 presentaron menos crecimiento $\left(1.00 \times 10^{4}\right.$ a $1.20 \mathrm{x}$ $10^{4} \mathrm{UFC} / \mathrm{ml}$ ), entendiendo que la capacidad de reproducción de las cepas BAL es variable en función a temperatura y condiciones del medio ${ }^{(29,35,36)}$.

Cuadro 1: Evaluación inicial de cepas aisladas para determinar características de BAL

\begin{tabular}{|c|c|c|c|c|c|c|c|c|c|c|}
\hline BAL & $\begin{array}{l}\text { Tam } \\
(\mathbf{m m})\end{array}$ & For & Ele & Mar & Col & Den & Con & Grupo & Forma & $\begin{array}{l}\text { Tamaño } \\
\text { UFC/ml }\end{array}$ \\
\hline $\begin{array}{l}\text { Cepa } \\
01\end{array}$ & P 1.72 & $\mathrm{C}$ & Convexa & $\mathrm{e}$ & B & $\mathrm{O}$ & Viscosa & Gram + & Bacilos & $2.60 \times 10^{4}$ \\
\hline $\begin{array}{l}\text { Cepa } \\
02\end{array}$ & P 1.82 & $\mathrm{C}$ & Convexa & $\mathrm{e}$ & B & $\mathrm{O}$ & Viscosa & Gram + & Cocobacilo & $1.70 \times 10^{4}$ \\
\hline $\begin{array}{l}\text { Cepa } \\
03\end{array}$ & $\begin{array}{c}\mathrm{M} \\
2.44\end{array}$ & $\mathrm{C}$ & Plana & $\mathrm{e}$ & B & $\mathrm{O}$ & Viscosa & Gram + & Bacilos & $1.10 \times 10^{4}$ \\
\hline $\begin{array}{l}\text { Cepa } \\
04\end{array}$ & P 1.28 & $\mathrm{C}$ & Plana & $\mathrm{e}$ & B & $\mathrm{O}$ & Viscosa & Gram + & Bacilos & $2.20 \times 10^{4}$ \\
\hline $\begin{array}{l}\text { Cepa } \\
05\end{array}$ & P 1.51 & $\mathrm{C}$ & Convexa & $\mathrm{e}$ & B & $\mathrm{O}$ & Viscosa & Gram + & Cocos & $2.80 \times 10^{4}$ \\
\hline $\begin{array}{l}\text { Cepa } \\
06\end{array}$ & $\begin{array}{l}\mathrm{M} \\
3.54\end{array}$ & $\mathrm{C}$ & Convexa & $\mathrm{e}$ & B & $\mathrm{O}$ & Viscosa & Gram + & Cocobacilo & $1.10 \times 10^{4}$ \\
\hline $\begin{array}{l}\text { Cepa } \\
07\end{array}$ & $\begin{array}{l}\mathrm{M} \\
3.54\end{array}$ & $\mathrm{C}$ & Convexa & $\mathrm{e}$ & B & $\mathrm{O}$ & Viscosa & Gram + & Cocos & $1.70 \times 10^{4}$ \\
\hline $\begin{array}{l}\text { Cepa } \\
08\end{array}$ & $\begin{array}{l}\text { D } \\
0.48\end{array}$ & $\mathrm{C}$ & Convexa & $\mathrm{e}$ & B & $\mathrm{O}$ & Viscosa & Gram + & Bacilos & $1.20 \times 10^{4}$ \\
\hline $\begin{array}{l}\text { Cepa } \\
09\end{array}$ & $\begin{array}{l}\mathrm{D} \\
0.48\end{array}$ & $\mathrm{C}$ & Plana & $\mathrm{e}$ & B & $\mathrm{O}$ & Viscosa & Gram + & Bacilos & $1.90 \times 10^{4}$ \\
\hline $\begin{array}{l}\text { Cepa } \\
10\end{array}$ & $\begin{array}{l}\mathrm{D} \\
0.48\end{array}$ & $\mathrm{C}$ & Plana & $\mathrm{e}$ & B & $\mathrm{O}$ & Viscosa & Gram + & Bacilos & $1.00 \times 10^{4}$ \\
\hline
\end{tabular}

\section{Evaluación del análisis bioquímico de las BAL}

Prueba de oxidasa, peróxido de hidrógeno, generación de gas y tolerancia a pH, NaCl y sales biliares. En el Cuadro 2, se observa que las 10 cepas fueron oxidasa negativa (no producen la enzima citocromo $\mathrm{C}$-oxidasa en su proceso de respiración), no son aeróbicas, por lo que no necesitan oxígeno en su membrana celular; éstas también presentaron reacción catalasa negativa (no reaccionar con el $\mathrm{H}_{2} \mathrm{O}_{2}$ ) y no produjeron $\mathrm{CO}_{2}$ $(7,16,24)$ (excepto 04, 08 y 10). En el experimento las cepas 03, 04, 08, 09 y 10, no lograron tener tolerancia a las concentraciones de $\mathrm{pH}, \mathrm{ClNa}$ y sales biliares, características de células probióticas $^{(19,23,29)}$, por lo que fueron descartadas definitivamente. 
Cuadro 2: Evaluación bioquímica y de tolerancia de cepas BAL como probiótico

\begin{tabular}{|c|c|c|c|c|c|c|c|c|c|c|c|c|}
\hline \multirow[t]{2}{*}{ Cepa } & \multirow[t]{2}{*}{ Oxi } & \multirow[t]{2}{*}{$\mathbf{p H}$} & \multirow[t]{2}{*}{ GG } & \multicolumn{3}{|c|}{$\begin{array}{c}\text { Tolerancia } \\
\text { pH }\end{array}$} & \multicolumn{3}{|c|}{$\begin{array}{c}\text { Tolerancia } \\
\text { CINa, \% }\end{array}$} & \multicolumn{3}{|c|}{$\begin{array}{c}\text { Tolerancia sales } \\
\text { biliares, } \%\end{array}$} \\
\hline & & & & 2.5 & 3.5 & 4.5 & 5 & 9 & 13 & 1 & 5 & 10 \\
\hline 01 & - & - & - & - & + & + & + & + & + & + & + & - \\
\hline 02 & - & - & - & - & + & + & + & - & - & + & + & - \\
\hline 03 & - & + & - & - & - & - & - & - & - & - & - & - \\
\hline 04 & - & - & + & - & - & - & - & - & - & - & - & - \\
\hline 05 & - & - & - & - & + & + & + & + & + & + & + & - \\
\hline 06 & - & - & - & - & + & + & + & + & + & + & + & - \\
\hline 07 & - & - & - & - & + & + & + & + & - & + & + & - \\
\hline 08 & - & - & + & - & - & - & - & - & - & - & - & - \\
\hline 09 & - & - & - & - & - & - & - & - & - & - & - & - \\
\hline 10 & - & - & + & - & - & - & - & - & - & - & - & - \\
\hline
\end{tabular}

En el Cuadro 3, se presenta la cantidad inicial y final en UFC/ml de las cepas sometidas a diferentes concentraciones de tolerancia con fines de selección, siendo la cepa 1 la que presentó mayor crecimiento final, seguida de las cepas 2,5 y 6 en pH 4.5 y 3.5, suficiente para selección ${ }^{(3,16,35)}$, pero, todas fueron susceptibles al medio de cultivo muy ácido ( $\mathrm{pH}$ 2.5). En el mismo cuadro, se presenta la tolerancia a $\mathrm{ClNa}$, donde la cepa 5, 1 y 6 evidenciaron mayor tolerancia en todas las concentraciones y las cepas 2 y 7 fueron susceptibles a la mayor concentración $(\mathrm{p} / \mathrm{v})$. También, se observa tolerancia a sales biliares en todas las cepas en concentración máxima de $5 \%$ motivo de selección ${ }^{(24,29,35)}$, donde la cepa 5 presentó mayor crecimiento $7.0 \times 10^{3} \mathrm{UFC} / \mathrm{ml}$, seguido de las cepas 6,1 , 2 y 7. 
Cuadro 3: Evaluación del recuento final de las colonias BAL (UFC/ml), según la tolerancia de cepas como probióticos

\begin{tabular}{|c|c|c|c|c|c|c|c|c|c|c|}
\hline \multirow{2}{*}{$\begin{array}{l}\text { Cep } \\
\text { a }\end{array}$} & & \multicolumn{3}{|c|}{ Tolerancia pH } & \multicolumn{3}{|c|}{ Tolerancia CINa, \% } & \multicolumn{3}{|c|}{$\begin{array}{c}\text { Tolerancia sales } \\
\text { biliares, } \%\end{array}$} \\
\hline & & 2.5 & 3.5 & 4.5 & 5 & 9 & 13 & 1 & 5 & 10 \\
\hline \multirow[t]{2}{*}{1} & $\begin{array}{l}\text { Inici } \\
\text { al }\end{array}$ & $\begin{array}{l}6.80 \times 1 \\
0^{3}\end{array}$ & $\begin{array}{l}7.90 \times 1 \\
0^{3}\end{array}$ & $\begin{array}{l}1.30 \times 1 \\
0^{4}\end{array}$ & $\begin{array}{l}2.85 \times 1 \\
0^{3}\end{array}$ & $\begin{array}{l}3.75 \times 1 \\
0^{3}\end{array}$ & $\begin{array}{l}3.25 \times 1 \\
0^{3}\end{array}$ & $\begin{array}{l}2.10 \mathrm{x} 1 \\
0^{4}\end{array}$ & $\begin{array}{l}9.40 \times 1 \\
0^{3}\end{array}$ & $\begin{array}{l}6.50 \times 1 \\
0^{3}\end{array}$ \\
\hline & Final & - & $\begin{array}{l}2.30 \times 1 \\
0^{4}\end{array}$ & $\begin{array}{l}3.80 \times 1 \\
0^{4}\end{array}$ & $\begin{array}{l}1.05 \times 1 \\
0^{4}\end{array}$ & $\begin{array}{l}1.19 \times 1 \\
0^{4}\end{array}$ & $\begin{array}{l}5.25 \times 1 \\
0^{3}\end{array}$ & $\begin{array}{l}6.40 \times 1 \\
0^{3}\end{array}$ & $\begin{array}{l}4.90 \times 1 \\
0^{3}\end{array}$ & - \\
\hline \multirow[t]{2}{*}{2} & $\begin{array}{l}\text { Inici } \\
\text { al }\end{array}$ & $\begin{array}{l}6.30 \times 1 \\
0^{3}\end{array}$ & $\begin{array}{l}7.20 \times 1 \\
0^{3}\end{array}$ & $\begin{array}{l}9.20 \times 1 \\
0^{3}\end{array}$ & $\begin{array}{l}2.50 \times 1 \\
0^{3}\end{array}$ & $\begin{array}{l}2.55 \times 1 \\
0^{3}\end{array}$ & $\begin{array}{l}2.90 \times 1 \\
0^{3}\end{array}$ & $\begin{array}{l}1.00 \times 1 \\
0^{4}\end{array}$ & $\begin{array}{l}8.60 \times 1 \\
0^{3}\end{array}$ & $\begin{array}{l}2.90 \times 1 \\
0^{3}\end{array}$ \\
\hline & Final & - & $\begin{array}{l}1.90 \times 1 \\
0^{4}\end{array}$ & $\begin{array}{l}2.90 \times 1 \\
0^{4}\end{array}$ & $\begin{array}{l}9.73 \times 1 \\
0^{3}\end{array}$ & - & - & $\begin{array}{l}6.30 \times 1 \\
0^{3}\end{array}$ & $\begin{array}{l}5.00 \times 1 \\
0^{3}\end{array}$ & - \\
\hline \multirow[t]{2}{*}{5} & $\begin{array}{l}\text { Inici } \\
\text { al }\end{array}$ & $\begin{array}{l}6,40 \times 1 \\
0^{3}\end{array}$ & $\begin{array}{l}7.50 \times 1 \\
0^{3}\end{array}$ & $\begin{array}{l}1.30 \times 1 \\
0^{4}\end{array}$ & $\begin{array}{l}5.03 \times 1 \\
0^{4}\end{array}$ & $\begin{array}{l}1.50 \times 1 \\
0^{4}\end{array}$ & $\begin{array}{l}7.56 \times 1 \\
0^{3}\end{array}$ & $\begin{array}{l}1.70 \times 1 \\
0^{4}\end{array}$ & $\begin{array}{l}1.40 \times 1 \\
0^{4}\end{array}$ & $\begin{array}{l}1.70 \times 1 \\
0^{4}\end{array}$ \\
\hline & Final & - & $\begin{array}{l}1.80 \times 1 \\
0^{4}\end{array}$ & $\begin{array}{l}2.30 \times 1 \\
0^{4}\end{array}$ & $\begin{array}{l}1.13 \times 1 \\
0^{4}\end{array}$ & $\begin{array}{l}2.80 \times 1 \\
0^{4}\end{array}$ & $\begin{array}{l}2.80 \times 1 \\
0^{4}\end{array}$ & $\begin{array}{l}1.10 \times 1 \\
0^{4}\end{array}$ & $\begin{array}{l}7.00 \times 1 \\
0^{3}\end{array}$ & - \\
\hline \multirow[t]{2}{*}{6} & $\begin{array}{l}\text { Inici } \\
\text { al }\end{array}$ & $\begin{array}{l}4.70 \times 1 \\
0^{3}\end{array}$ & $\begin{array}{l}6.50 \times 1 \\
0^{3}\end{array}$ & $\begin{array}{l}1.30 \times 1 \\
0^{4}\end{array}$ & $\begin{array}{l}4.67 \times 1 \\
0^{3}\end{array}$ & $\begin{array}{l}5.20 \times 1 \\
0^{3}\end{array}$ & $\begin{array}{l}3.25 \times 1 \\
0^{3}\end{array}$ & $\begin{array}{l}1.20 \times 1 \\
0^{4}\end{array}$ & $\begin{array}{l}7.10 \times 1 \\
0^{3}\end{array}$ & $\begin{array}{l}6.20 \times 1 \\
0^{3}\end{array}$ \\
\hline & Final & - & $\begin{array}{l}1,80 \times 1 \\
0^{4}\end{array}$ & $\begin{array}{l}2.30 \times 1 \\
0^{4}\end{array}$ & $\begin{array}{l}9.80 \times 1 \\
0^{3}\end{array}$ & $\begin{array}{l}1,00 \times 1 \\
0^{4}\end{array}$ & $\begin{array}{l}5.25 \times 1 \\
0^{3}\end{array}$ & $\begin{array}{l}7.50 \times 1 \\
0^{3}\end{array}$ & $\begin{array}{l}5.80 \times 1 \\
0^{3}\end{array}$ & - \\
\hline \multirow[t]{2}{*}{7} & $\begin{array}{l}\text { Inici } \\
\text { al }\end{array}$ & $\begin{array}{l}4.50 \times 1 \\
0^{3}\end{array}$ & $\begin{array}{l}5.50 \times 1 \\
0^{3}\end{array}$ & $\begin{array}{l}1.00 \times 1 \\
0^{4}\end{array}$ & $\begin{array}{l}4.50 \times 1 \\
0^{3}\end{array}$ & $\begin{array}{l}4.80 \times 1 \\
0^{3}\end{array}$ & $\begin{array}{l}3.00 \times 1 \\
0^{3}\end{array}$ & $\begin{array}{l}7.10 \times 1 \\
0^{3}\end{array}$ & $\begin{array}{l}4.50 \times 1 \\
0^{3}\end{array}$ & $\begin{array}{l}5.00 \times 1 \\
0^{3}\end{array}$ \\
\hline & Final & - & $\begin{array}{l}9.50 \times 1 \\
0^{3}\end{array}$ & $\begin{array}{l}2.00 \times 1 \\
0^{4}\end{array}$ & $\begin{array}{l}7.50 \times 1 \\
0^{3}\end{array}$ & $\begin{array}{l}5.50 \times 1 \\
0^{3}\end{array}$ & - & $\begin{array}{l}5.30 \times 1 \\
0^{3}\end{array}$ & $\begin{array}{l}3.80 \times 1 \\
0^{3}\end{array}$ & - \\
\hline
\end{tabular}

Prueba negativa: - UFC=unidad formadora de colonias $\mathrm{BAL}=\mathrm{UFC} / \mathrm{ml}$.

Las BAL encontradas en el estudio demostraron características probióticas evaluadas según la tolerancia a concentraciones bajas de $\mathrm{pH}$, lo que coincide con la mayoría de autores, que consideran sobrevivencia a pH 3 a 3.4 y un óptimo pH 3.5 $5^{(14,35,36)}$. También presentaron tolerancia a concentraciones altas de sales biliares y $\mathrm{NaCl}$ como las encontradas en otras investigaciones ${ }^{(7,35,36)}$, condiciones que son consideradas obligatorias como probióticas encontrando que las cepas $\operatorname{BAL}(5,1,2$ y 6) presentaron ser viables para su selección como probióticas según la metodología realizada por otros investigadores $^{(16,37,38) \text {. }}$

\section{Evaluación del análisis molecular. Secuenciación de ADN}

En el Cuadro 4 se presenta la identificación molecular de las cepas BAL y bacterias patógenas del trabajo con alto porcentaje de identidad (99\%). 
Cuadro 4: Identificación molecular mediante el gen 16S ARNr de cepas extraídas de la parte final del tracto gastrointestinal del lechón

\begin{tabular}{llllc}
\hline Cepas & $\begin{array}{c}\text { Tamaño de } \\
\text { secuencia }(\mathbf{p b})\end{array}$ & Especie identificada & $\begin{array}{c}\text { Identidad } \\
\text { \% }\end{array}$ & $\begin{array}{c}\mathbf{N}^{\circ} \text { de } \\
\text { accesión }\end{array}$ \\
\hline BAL 01 & 1371 & Lactobacillus reuteri & 99 & NR075036.1 \\
BAL 02 & 1328 & Enterococcus faecium & 99 & NR113904.1 \\
BAL 05 & 1344 & Enterococcus faecium & 99 & NR113904.1 \\
BAL 06 & 1366 & Enterococcus faecium & 99 & NR113904.1 \\
BAL 07 & 1383 & Enterococcus faecium & 99 & NR113904.1 \\
(A) & 1352 & Escherichia fergusonii & 99 & NR074902.1 \\
(B) & 1359 & Shigella flexneri & 99 & NR026331.1 \\
\hline
\end{tabular}

Las cepas BAL, E. faecium y L. reuteri, encontradas e identificadas molecularmente, están presentes como microorganismos nativos del tracto digestivo del cerdo y tienen efecto antagónico contra Escherichia, semejante también con la evaluación del E. faecium NCIMB 10415 y E. faecium NCIMB $11181^{(38,39,40)}$ y el L. reuteri 15007 y L. reuteri KT260178, Lactobacillus sp, L. acidophilus, utilizados como probióticos en la producción porcina $^{(29,41,42)}$.

Las muestras de bacterias patógenas de lechones, (Cuadro 4) son reportadas con mayor incidencia en la crianza de $\operatorname{cerdos}^{(39,40)}$.

\section{Evaluación de la actividad inhibitoria de las BAL contra bacterias patógenas}

Al comparar los tres métodos para determinar la actividad inhibitoria (Cuadro 5), se observa que el método directo y de pocillo neutralizado, presentan menor inhibición que el de pocillo sin neutralizar, ya que este último tiene $\mathrm{pH}$ ácido como consecuencia de los ácidos orgánicos presentes, los cuales tienen actividad bactericida ${ }^{(29,35,41)}$.

El E. faecium y L. reuteri, tuvieron mayor actividad antagónica frente a la E. fergunsonii que es más susceptible que a $S$. flexneri como los reportados por otros ${ }^{(12,38,39)}$; así también la Eschericha es susceptible a la mayoría de bacterias acido lácticas como son a cepas de Lactobacillus spp extraídos de terneros lactantes, L. plantarum aislados de cerdos criollos y L. lactis aislados de lechones ${ }^{(40,41,42)}$.

Método directo, los resultados del Cuadro 5, muestran el efecto inhibitorio por contacto directo de las BAL. Las cepas 5, 6 y 7 mostraron inhibición contra las dos cepas patógenas, con mayor tamaño de halos frente a E. fergunsonii, destacando la cepa 5 con halo de $8.46 \pm 3.02$. Las cepas 1 y 2 presentaron menores halos frente a las patógenas ${ }^{(38,41)}$. 
Cuadro 5: Tamaño de halo de las pruebas de inhibición de BAL contra los patógenos de Shigella flexneri y Escherichia fergusonii

\begin{tabular}{lllllll}
\hline & \multicolumn{3}{c}{ Escherichia fergusonii } & \multicolumn{3}{c}{ Shigella flexneri } \\
\cline { 2 - 7 } Cepas & Directo & $\begin{array}{c}\text { Sin } \\
\text { neutralizar }\end{array}$ & Neutralizado & Directo & $\begin{array}{c}\text { Sin } \\
\text { neutralizar }\end{array}$ & Neutralizado \\
& & & & & \\
01 & $6.52 \pm 0.132$ & $7.54 \pm 0.43$ & $6.85 \pm 036$ & 6.00 & $6.30 \pm 0.56$ & 6.00 \\
02 & $6.94 \pm 0.44$ & $7.90 \pm 0.078$ & $7.10 \pm 0.60$ & 6.00 & $7.34 \pm 0.05$ & 6.00 \\
05 & $8.46 \pm 3.02$ & $8.86 \pm 0.62$ & $8.76 \pm 3.80$ & $6.9 \pm 0.45$ & $10.34 \pm 0.13$ & $7.34 \pm 0.89$ \\
06 & $8.33 \pm 2.70$ & $9.72 \pm 1.88$ & $8.52 \pm 3.17$ & $6.72 \pm 0.259 .84 \pm 0.40$ & $6.84 \pm 0.35$ \\
07 & $8.25 \pm 2.53$ & $9.24 \pm 0.60$ & $8.65 \pm 3.51$ & $6.24 \pm 0.0210 .10 \pm 2.0$ & $7.10 \pm 0.60$ \\
\hline \multicolumn{5}{c}{ Prueba negativa: 6.00} \\
\end{tabular}

Método de pocillo, sin neutralizar, la prueba se realizó con el sobrenadante del cultivo de las BAL, con $\mathrm{pH}$ promedio de $4.486 \pm 0.001$. En el Cuadro 5, se observa que todas las cepas presentan halos de inhibición en el enfrentamiento contra E. fergusonii, sobresaliendo las cepas 6 y 7 , seguido de la cepa 5 y finalmente las cepas 2 y 1 . Los halos formados frente a $S$. flexneri fueron de mayor tamaño frente al otro patógeno, siendo las cepas (ordenadas de mayor a menor tamaño) 5, 7, 6, 2 y 1 respectivamente.

Las BAL 5, 7 y 6 (E. faecium) presentaron mayores halos frente a $S$. flexneri, resultados semejantes y menores a los obtenidos en prueba con Lactobacillus spp, enfrentados a patógenos del cerdo, presentando halos desde $11.24 \pm 0.03$ a $32.62 \pm 0.04$ frente a la Salmonella $s p$ han sido reportados ${ }^{(19,36,41)}$. En pruebas utilizando el sobrenadante bacteriano sin neutralizar, tiene mayor acción de inhibición, debido al efecto de los ácidos orgánicos según las pruebas de antagonismo ${ }^{(29,35,40)}$.

Método de pocillo neutralizado, para este caso el sobrenadante del cultivo de las BAL se ajustó a pH 7.00 (neutralizado con hidróxido de sodio) con el fin de excluir la inhibición de los ácidos orgánicos. Todas las cepas presentaron halos (Cuadro 5), en el enfrentamiento con E. fergusonii, pero en menor tamaño que la prueba sin neutralizar, siendo los halos mayores para las cepas 5,7 y 6, en la prueba con $S$. flexneri. En este método al no haber acción ácida se atribuye la acción antimicrobiana a la presencia de metabolitos no ácidos. Se reporta que las BAL producen sustancias peptídicas que producen un modo de acción bactericida o bacteriostático ${ }^{(16,42)}$, lo que también está referido a la actividad de metabolitos proteicos o moléculas complejas lipídicas o carbohidratos $^{(11)}$.

Las cepas 5, 6 y 7 (E. faecium) evaluados, presentaron en los tres métodos los mayores halos frente a $E$. fergunsonii, siendo el método de pocillo sin neutralizar las que generaron mayores halos, semejante a lo ya reportado ${ }^{(11,16)}$. El antagonismo de la BAL está influenciado por varios factores como son el tipo de bacteria, lugar de donde ésta se obtuvo, especie hospedera, temperatura y tiempo de incubación ${ }^{(14,15,41)}$. Las BAL con 
actividad probiótica presentaron antagonismo frente a patógenos del cerdo y su acción se compara con la mayoría de probióticos obtenidos de bacterias Lactobacillus ssp. L. acidophilus, L. plantarum, $(\text { L. casei y L. brevis })^{(14,19,29)}$, que actúan frente a la bacteria patógena E. coli ATCC 25922 y S. typhimurium ${ }^{(14)}$.

\section{Evaluación del inóculo lácteo}

Evaluación físico-química (pH, acidez y sinéresis). De la evaluación de las BAL como probiótico quedaron seleccionadas las cepas 1, 2, 5 y 6 con los cuales se preparó dos mezclas como IL (yogur), en la primera mezcla se utilizaron las cepas 1, 2, y 5 y en la segunda las cepas 1,5 y 6, (1 ml de cepa activada en $100 \mathrm{ml}$ de leche), utilizando $50 \mathrm{ml}$ de cada cepa según la mezcla, para evaluar su viabilidad, a los 0, 5, 10 y 15 días de almacenamiento hasta su uso como IL (yogurt). En el Cuadro 6, se observó que la mezcla uno presentó mejor estabilidad, donde los valores del $\mathrm{pH}$ fueron inversamente proporcional a la acidez, la cual disminuye en función a los días de refrigeración, llegando a los 15 días con pH de 4.53 y pH 4.78 de la mezcla uno y dos respectivamente, valores que están en los parámetros aceptables de estabilidad y vida útil, relacionado con el tiempo de degradación de la lactosa a ácido láctico. Los resultados obtenidos son aceptables, comparables al pH de 4.65 obtenido en la fabricación de yogur con leche de cabra o vaca utilizando microorganismos fermentadores comerciales y yogures simbióticos $^{(26,27)}$, así mismo cumple con la norma del Codex stan $243-2003^{(43)}$, la cual refiere que todos los yogures deben tener un $\mathrm{pH} \leq \mathrm{a} 4.6$, hasta un $\mathrm{pH}$ de 4.90, valores semejantes a los yogures y productos lácteos no tradicionales ${ }^{(25,27,30)}$, el $\mathrm{pH}$ obtenido fue semejante a fermentos lácteos para cerdos, ensilados con productos lácteos que mantienen los $\mathrm{pH}$ entre 3 a 4.9 ${ }^{(18,35,44)}$. A pesar de que la mezcla dos presentó $\mathrm{pH}$ ligeramente mayor, este también se encuentra dentro de las normas técnicas, NTP 202.092:2014 y Norma INEN 710 de $1996^{(20)}$, el pH se modifica en mayor rango al incorporar fibra de trigo y otros granos en yogures artesanales mexicanos ${ }^{(18,32,33)}$. A pesar de que el yogurt este en refrigeración, se detiene el crecimiento de las cepas BAL, sin embargo, la acidez continúa lentamente por su actividad residual ${ }^{(26,30,31)}$, se aumenta la vida útil al incorporar frutas ácidas y batidos con pectina ${ }^{(27,34)}$, también se mejora la calidad y sabor agregando frutas con componentes funcionales (lúcuma, plátano, mango y otros) ${ }^{(34,45)}$, por lo tanto, el pH en la incubación y almacenamiento del IL determina su aceptabilidad para ser utilizado $^{(31)}$. 
Cuadro 6: Evaluación de $\mathrm{pH}, \%$ acidez, grado de sinéresis y recuento viable de BAL de los IL (yogur) a diferentes días de almacenamiento a $4{ }^{\circ} \mathrm{C}$

Mezcla $01 \quad$ Mezcla 02

\begin{tabular}{ccccccccc}
\hline Días & pH & $\begin{array}{c}\text { Acidez } \\
\text { \% }\end{array}$ & $\begin{array}{c}\text { Sinéresis } \\
\text { \% }\end{array}$ & UFC/g & Ph & Acidez \% Sinéresis & UFC/g & UFC \\
\cline { 2 - 8 } 0 & 4.65 & 0.80 & 0.36 & $4.8 \times 10^{6}$ & 4.94 & 0.47 & 0.39 & $2.8 \times 10^{4}$ \\
5 & 4.61 & 0.86 & 0.49 & $1.5 \times 10^{7}$ & 4.88 & 0.50 & 0.45 & $7.4 \times 10^{4}$ \\
10 & 4.57 & 0.90 & 0.55 & $2.7 \times 10^{7}$ & 4.82 & 0.55 & 0.53 & $9.6 \times 10^{4}$ \\
15 & 4.53 & 0.93 & 0.61 & $3.9 \times 10^{7}$ & 4.78 & 0.58 & 0.58 & $1.1 \times 10^{6}$ \\
\hline
\end{tabular}

El valor de la acidez (\%) está en función al contenido de ácido láctico, llegando hasta 0.93 y $0.58 \%$ valores considerados aceptables como producto lácteo según la norma de preparación del yogurt de acuerdo a lo establecido por Codex stan $243-2003^{(44)}$, Norma INEN 710 de 1996, tiene un rango final entre 0.6 a $1.5 \%$ durante la refrigeración ${ }^{(20)}$, el porcentaje de acidez obtenido es aceptada en alimentos fermentados y ensilados ${ }^{(28,35,44)}$. El grado de sinéresis medido de los IL (yogur) aumentó lentamente durante su almacenamiento, efecto debido a la pérdida de estabilidad, retención de agua y de sus componentes. En el Cuadro 6 se presentan los valores de la evaluación del grado de sinéresis durante su almacenamiento, a 15 días de refrigeración presentó un rango aceptable de 0.36 a $0.61 \%$ (mezcla uno y dos), resultados semejantes a los obtenidos en yogur y batido de leche de cabra con frutas ${ }^{(26,27,34)}$, pero son mayores a yogures modificados, por la adición de estabilizantes comerciales, microcápsulas de goma arábiga y maltodextrina $(0.12 \text { a } 0.1 \%)^{(27,30)}$ y fibra que ayuda a prevenir la separación de lactosuero ${ }^{(32,33)}$.

Evaluación microbiológica. En el Cuadro 6, se presenta la viabilidad de BAL como probióticos en el IL (yogurt), la mezcla uno, muestra mayor aumento de microorganismos probióticos que la mezcla dos, durante su evolución en refrigeración. El recuento de las BAL en ambas mezclas es semejante a lo que recomienda la NTP 202.092:2014, utilizando el método ISO 7889:2003 (IDF 117:2003) para la preparación de yogurt ${ }^{(33)}$, considerando como mínimo para número de microorganismo de bacterias lácticas totales en el yogurt, durante su vida útil de $10^{7} \mathrm{UFC} / \mathrm{g}$, obtenidos por la mezcla uno y dos a los 15 días de refrigeración (3.9 x $10^{7} \mathrm{UFC} / \mathrm{g}$ y 1.1 x $10^{6} \mathrm{UFC} / \mathrm{g}$ respectivamente), garantizando que el producto elaborado, contiene y conserva su viabilidad y actividad probiótica como en la fabricación de los diferentes yogures utilizando leche de cabra o de vaca, bacterias fermentadores comerciales, saborizantes, frutas y fibra, con una concentración de $10^{7} \mathrm{UFC} / \mathrm{g}$ a $10^{6} \mathrm{UFC} / \mathrm{g}$ de células probióticas viables en los 16 primeros días ${ }^{(30,34,46)}$. Actualmente el consumidor demanda alimentos funcionales (frutas antioxidantes $)^{(33,45)}$, menos procesados y más naturales, así también se busca mejorar su vida útil proporcionando cualidades antimicrobianas utilizando bacterias nativas benéficas $^{(17,18,42)}$. La reuterina, producida por $L$. reuteri, es un antibacteriano que puede ser utilizado como un bioconservante con potencial probiótico controlador de Salmonella 
spp. y E. coli en alimentos para personas o animales, la tendencia es el uso de las BAL nativas y sus extractos bacterianos como potenciales probióticos aislados y utilizados en la misma especie animal ${ }^{(12,38,39)}$.

\section{Conclusiones e implicaciones}

La caracterización bioquímica, las pruebas de tolerancia y efecto antagónico de las BAL seleccionadas, fueron de gran importancia en el crecimiento y supervivencia de cuatro cepas probióticas (tres Enterococcus faecium y una cepa Lactobacillus reuteri), destacando la producción de ácidos orgánicos presente en los sobrenadantes sin neutralizar para su actividad antimicrobiana y existe acción no ácida por metabólicos en sobrenadantes neutralizados con efecto bactericida. Con las cepas aisladas se logró elaborar un inóculo lácteo (yogur) con características aceptables, viables e inocuas para ser considerado como probiótico potencial de administración oral, con 15 días de vida útil.

\section{Agradecimientos}

A la Universidad Nacional de Tumbes, por su apoyo incondicional a la investigación y al personal obrero de la FCA

\section{Literatura citada:}

1. Hevia RM. Microbiota digestiva del cerdo: determinación del patrón en condiciones de salud y enfermedad [tesis doctoral]. León, España: Universidad de León; 2018.

2. Balasingham K, Valli C, Radhakrishnan L. Balasuramanyam D. Caracterización probiótica de bacterias del ácido láctico aisladas de intestino porcino. Mundo Vet $2017 ; 10(7): 825$.

3. Gámez HJ, Aguirre D, Ramírez CJRMC. Caracterización de bacterias probióticas aisladas del intestino grueso de cerdos como alternativa al uso de antibióticos. Rev MVZ Córd 2009;14(2):1723-1735.

4. Miranda-Yuquilema JE, Marin-Cárdenas A, Oliva-Bello H, Baño-Ayala D, BarrosRodríguez M, Jácome-Vargas H, Villamarín-Barragán D. Influence of a microbial additive on the productive behavior of pregnant sows, as well as, hematochemical and diarrheal incidence in their offspring. Trop Subtrop Agroecosyst 2018;21(1):3945 .

5. Reis de Souza TC, Mariscal Landín G, Escobar García K, Aguilera Barreyro A, Magné Barrón A. Cambios nutrimentales en el lechón y desarrollo morfoisiológico de su aparato digestivo. Vet Méx 2012;43(2):155-173. 
6. Pérez FA. Prácticas de manejo del lechón en maternidad: estrategias para mejorar su sobrevida y aumentar la productividad. Rev Electr Vet 2010;11(1):177-190.

7. Cossio DS, Hernández YG, Mendoza JD. Development of probiotics for animal production. experience in Cuba. Cuba J Agric Sci 2018;52(4):357-373.

8. Quintero MJV. Bacterias del ácido láctico un potencial para la producción de alimentos probióticos fermentados en la industria láctea de Panamá. KnE Eng 2018;3(1):38-47.

9. Ávila J, Ávila M, Tovar B, Brizuela M, Perazzo Y, Hernández H. Capacidad probiótica de cepas del género Lactobacillus extraídas del tracto intestinal de animales de granja. Rev Cienc 2010;20(2):161-169.

10. Martín C, Escobedo S, Suárez JE, Quirós LM, Pérez-Martínez G, Coll-Marqués JM, et al. Two alkaline motifs in the lactobacillus salivarius Lv72 OppA surface are important to its adhesion function. Benefic Microbiol 2019;10(1):101-109.

11. Lu X, Zhang M, Zhao L, Ge K, Wang Z, Jun L, et al. Growth performance and postweaning diarrhea in piglets fed a diet supplemented with probiotic complexes. J Microbiol Biotechnol 2018;28(11):1791-1799.

12. Chengjun H, Weigang X, Xiaohua L, Xiuzhu Z, Ke L, Jia L, et al. Effects of dietary supplementation of probiotic Enterococcus faecium on growth performance and gut microbiota in weaned piglets. AMB Express. 2019;9(1):11-12.

13. Fengjuan Y, Aina W, Xiangfang Z, Chengli H, Hong L, Shiyan Q. Lactobacillus reuteri 15007 modulates tight junction protein expression in IPEC-J2 cells with LPS stimulation and in newborn piglets under normal conditions. BMC Microbiology 2015;15(1):10-11.

14. Vera-Mejía R, Ormaza-Donoso J, Muñoz-Cedeño J, Arteaga-Chávez F, SánchezMiranda L. Cepas de Lactobacillus plantarum con potencialidades probióticas aisladas de cerdos criollos. Rev Salud Anim 2018;40(2):11-12.

15. Sánchez SH, Ochoa MG, Rojas MC, Peralta OT, Ordinola ZA. Aislamiento de péptidos inhibidores de bacterias a partir de bacterias ácido lácticas del tracto digestivo del lechón e identificación mediante prueba proteómica. Sci Agropec 2017;8(4):437-443.

16. Vélez Zea JM. Evaluación de la actividad antimicrobiana de bacterias probióticas extraídas del calostro de cerdas de granjas del Aburrá sur [tesis doctoral]. Medellín, Colombia: Universidad Nacional de Colombia-Sede Medellín; 2015.

17. Barón LVC. Probióticos y prebióticos como alimentos funcionales en nutrición animal. Zoocienc 2016;3(2):15-21. 
18. Medina PJG. Propiedades tecnológicas de bacterias ácido lácticas aisladas de productos lácteos fermentados artesanales expendidos en la región Ciénega de Jalisco. Adv Invest Food Saf 2018;1(1):230-234.

19. Ming-Lun C, Hsi-Chia C, Kun-Nan C, Yu-Chun L, Ya-Ting L, Ming-Ju C. Optimizing production of two potential probiotic Lactobacilli strains isolated from piglet feces as feed additives for weaned piglets. Asian-Austral J Anim Sci 2015;28(8):1163-1170.

20. Landa-Salgado P, Caballero-Cervantes Y, Ramírez-Bribiesca E, HernándezAnguiano AM, Ramírez-Hernández LM, Espinosa-Victoria D, Hernández-Sánchez D. Aislamiento e identificación de bacterias ácido lácticas con potencial probiótico para becerros del altiplano mexicano. Rev Mex Cienc Pecu 2019;10(1):68-83.

21. Flores Fuentes GD. Propuesta de un manual de procedimientos operativos estándar sobre la toma de muestras de alimentos para uso de la Defensoría del Consumidor [tesis doctoral]. El Salvador: Universidad de El Salvador; 2015.

22. Botero Ospina MJ, Castaño DRT, Castaño Zapata J. Manual práctico de microbiología general. No. Doc. 26157. CO-BAC, Bogotá. 2011.

23. MacFaddin JF. Pruebas bioquímicas para la identificación de bacterias de importancia clínica: Métodos microbiológicos. Capítulo 17. 18a. ed: Editorial Panamericana; 2002.

24. Arteaga-Chávez F, López-Vera M, Laurencio-Silva M, Rondón-Castillo A, MiliánFlorido G, Barrios-González V. Selección e identificación de aislados de Bacillus spp. del tracto digestivo de pollos de traspatio, con potencial probiótico. Pastos y Forrajes 2017:155-164.

25. ECUADOR NTE INEN IJR, Quito, Ecuador. Instituto Ecuatoriano de Normalización Norma técnica Ecuatoriana del Yogurt INEN 2395:2011.https://www.normalizacion.gob.ec/buzon/normas/nte-inen-2395-2r.pdf. consultado nov 15, 2018.

26. Zapata IC, Sepúlveda-Valencia U, Rojano BA. Efecto del tiempo de almacenamiento sobre las propiedades fisicoquímicas, probióticas y antioxidantes de yogurt saborizado con mortiño (Vaccinium meridionale Sw). Inf Tech 2015;26(2):17-28.

27. Ortega LAJ, Ramírez LB, Rodríguez EA. Desarrollo y evaluación de un yogurt bebible adicionado de extracto liofilizado de Justicia spicigera como colorante natural. e-CUBA 2018;(9):25-34.

28. Miranda MO, Espinosa REN, Ponce PI. Características físico-químicas y propiedades nutricionales del suero resultante del proceso de obtención del yogurt Griego. Rev Cubana Alim Nutri 2016;26(1):172-174. 
29. Hernández-García JE, Sebastián-Frizzo L, Rodríguez-Fernández JC, Valdez-Paneca G, Virginia-Zbrun M, Calero-Herrera I. Evaluación in vitro del potencial probiótico de Lactobacillus acidophilus SS80 y Streptococcus thermophilus SS77. Rev Salud Anim 2019;41(1):1-13.

30. Huertas RAP. Efecto del té verde (Camellia Sinensis L.) en las características fisicoquímicas, microbiológicas, proximales y sensoriales de yogurt durante el almacenamiento bajo refrigeración. @ limentech, Cient Tech food 2013;11(1):5664.

31. Sánchez J, Enríquez D, Castro PJAS. Efecto de la concentración de sólidos totales de la leche entera y tipo de cultivo comercial en las características reológicas del yogurt natural tipo batido Agroind Sci 2012;2(2):173-80.

32. Díaz Jiménez B, Sosa Morales M, Vélez Ruiz J. Efecto de la adición de fibra y la disminución de grasa en las propiedades fisicoquímicas del yogur. Rev Mex Ing Quím 2004;3(3):287-305.

33. Simanca MM, Andrade RD, Arteaga MR. Efecto del salvado de trigo en las propiedades fisicoquímicas y sensoriales del yogurt de leche de búfala. Inf Tech 2013;24(1):79-86.

34. Vásquez-Villalobos V, Aredo V, Velásquez L, Lázaro M. Propiedades fisicoquímicas y aceptabilidad sensorial de yogur de leche descremada de cabra frutado con mango y plátano en pruebas aceleradas. Sci Agropecu 2015;6(3):177189.

35. Sánchez SH, Fabián DF, Ochoa MG, Alfaro AR. Sucesión bacteriana del tracto digestivo del lechón alimentado con ensilado biológico. Rev Inv Vet Perú 2019;30(1):214-223.

36. Ng SY, Koon SS, Padam BS, Chye FY. Evaluation of probiotic potential of lactic acid bacteria isolated from traditional Malaysian fermented Bambangan (Mangifera pajang). CyTA: J Food 2015;13(4):563-572.

37. Jurado GH, Aguirre FD, Ramírez TC. Caracterización de bacterias probióticas aisladas del intestino grueso de cerdos como alternativa al uso de antibióticos. Rev MVZ Córdova 2009;4(2):1723-1735.

38. Kern M, Aschenbach JR, Tedin K, Pieper R, Loss H, Lodemann U. Characterization of inflammasome components in pig intestine and analysis of the influence of probiotic Enterococcus faecium during and Escherichia coli challenge. Immunology Res 2017;46(7):742-757.

39. Chae JP, Pajarillo EAB, Oh JK, Kim H, Kang DK. Revealing the combined effects of lactulose and probiotic enterococci on the swine faecal microbiota using 454 pyrosequencing. Microb Biotechnol 2016;9(4):486-495. 
40. Dowarah R, Verma AK, Agarwal N, Singh P, Singh BR. Selection and characterization of probiotic lactic acid bacteria and its impact on growth, nutrient digestibility, health and antioxidant status in weaned piglets. PLoS One 2018;13(3):1-24.

41. Estrada MAC, Gutiérrez RLA, Montoya COI. Evaluación in vitro del efecto bactericida de cepas nativas de Lactobacillus sp. contra Salmonella sp. y Escherichia coli in vitro. Rev FNAgron Medellín 2005;58(1):2601-2609.

42. Andrea M. Probióticos y su mecanismo de acción en alimentación animal. Agron Mesoamericana 2019;30(2):601-611.

43. Codex para leches fermentadas. Leche y productos lácteos segunda edición. STAN 243-2003. www.fao.org/3/a-i2085s.pdf. Consultado nov 20, 2018.

44. Caicedo WO, Moyano JC, Valle SB, Díaz LA, Caicedo ME. Calidad fermentativa de ensilajes líquidos de chontaduro (Bactris gasipaes) tratados con yogur natural, suero de leche y melaza. Rev Inv Vet Perú 2019;30(1):167-177.

45. Paucar-Menacho LM. Lúcuma (Pouteria lucuma): Composición, componentes bioactivos, actividad antioxidante, usos y propiedades beneficiosas para la salud. Sci Agropec 2020;11(1):135-142.

46. Benítez-de la Torre A, Montejo-Sierra IL, Morales-García YE, Muñoz-Rojas J, Díaz-Ruíz R, López PA. Adición de fuentes energéticas e inoculantes en la elaboración de yogurt de yuca. Pastos Forrajes 2018;4(1):30-34. 